\title{
Novel Immunomodulatory Markers Expressed by Human WJ-MSC: an Updated Review in Regenerative and Reparative Medicine
}

\author{
Giampiero La Rocca ${ }^{1,2 *}$, Simona Corrao ${ }^{2 \S}$, Melania Lo Iacono ${ }^{2}$, Tiziana Corsello ${ }^{2}$, Felicia Farina ${ }^{1}$ \\ and Rita Anzalone ${ }^{1}$
}

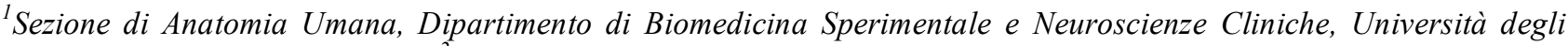
Studi di Palermo, Palermo, Italy, ${ }^{2}$ Istituto Euro-Mediterraneo di Scienza e Tecnologia (IEMEST), Palermo, Italy

\begin{abstract}
Mesenchymal (stromal) stem cells (MSC) are a broad class of stromal populations which are able to differentiate towards mature cell types, and do express molecules involved in immune modulation, tolerance induction and inflammation dampening. MSC can be virtually isolated from each adult organ, as well as from foetus-associated perinatal tissues. In particular, Wharton's jelly-derived MSC (WJ-MSC) bear all of these key properties, together with their ease of sourcing and lack of ethical issues.

Cellular therapy is a key technique in regenerative medicine approaches, in particular for the treatment of diseases in which physiological processes of cellular repopulation are blocked by the underlying pathological conditions. Recent data enlightened the ability of administered cells to act also in a repopulation-independent fashion in target organs, since their peculiar immunomodulatory and anti-inflammatory features may favor organ self-repair by reactivating local progenitors by both cell-mediated or paracrine mechanisms. Translating classical regenerative medicine to "reparative medicine" or "support medicine" should represent a further therapeutic strategy independent from the differentiation capacity of MSC populations.

Recent data further highlighted that WJ-MSC outperform BM-MSC (which are now being applied clinically) both in terms of immune modulation and lack of tumorigenesis (or tumor-promoting activities) in vivo. Starting from these premises, this paper analyzes the recent data on the biology of WJ-MSC, considering the role of both naïve and differentiated cells in immune modulation. In particular, the role of tolerance promoting pathways via non-classical B7 costimulators or class Ib MHC molecules are examined. In addition, we also analyzed the interconnections with other mechanicistic pathways (as those driven by matrix degrading metalloproteinases) in immune modulation. Our observations strongly support the notion that WJ-MSC may constitute a new tool in regenerative and reparative medicine applications.
\end{abstract}

Keywords: Mesenchymal stem cells, Wharton's jelly, immune modulation, umbilical cord, hypoimmunogenicity, differentiation, inflammation, matrix metalloproteinases, regenerative medicine, tissue repair.

\section{INTRODUCTION}

Perinatal stem cells research attracted a great interest worldwide in recent years. Foetus-associated tissues contain various populations of stem cells, most of which are comprised within the category of mesenchymal stem cells (MSC). Many advantages of using perinatal tissues as sources of stem cells, can be listed: ease of the isolation process, lack of risks for donors, lack of ethical issues and high cellular yield. Data from many reports showed that cellular isolation is achieved in nearly $100 \%$ specimens. Perinatal MSC may be easily sub-cultured and long-term stored by deep-freezing techniques.

*Address correspondence to this author at Sezione di Anatomia Umana, Dipartimento di Biomedicina Sperimentale e Neuroscienze Cliniche, Università degli Studi di Palermo, Via del Vespro 129, Palermo, PA 90127, Italy; Tel: 00390916553506; Fax: 00390916553580;

E-mails: giampylr@hotmail.com; giampiero.larocca@unipa.it

$\S$ Both authors contributed equally
The umbilical cord (UC) is a key part of placenta, the organ providing foetus-maternal interface during pregnancy. In particular, $\mathrm{UC}$ is an extraembryonic mesoderm formation that originates at day 13 of the embryonic development [1]. The mature umbilical cord is constituted by three vessels, one vein and two arteries, which are comprised into a meshwork formed by a mature mucous connective tissue, named Wharton's jelly (WJ), by the name of Thomas Wharton who described the tissue in seventeenth century. Vessels inside UC provide both gas and nutrients exchange to the foetal circulation. Other than the major vessels, UC present neither other vascular structures nor neural elements [2].

While WJ constitutes the largest amount of UC bulk tissue, this anatomical formation is actually constituted by different zones. Structural and functional studies led to the description of at least 5 distinct zones in human UC: amniotic epithelium, subamniotic stroma, intervascular stroma (WJ), perivascular stroma, and vessels. In the classical view, WJ is populated by two main cellular types: fibroblast-like cells [3] and myofibroblasts [4, 5]. 


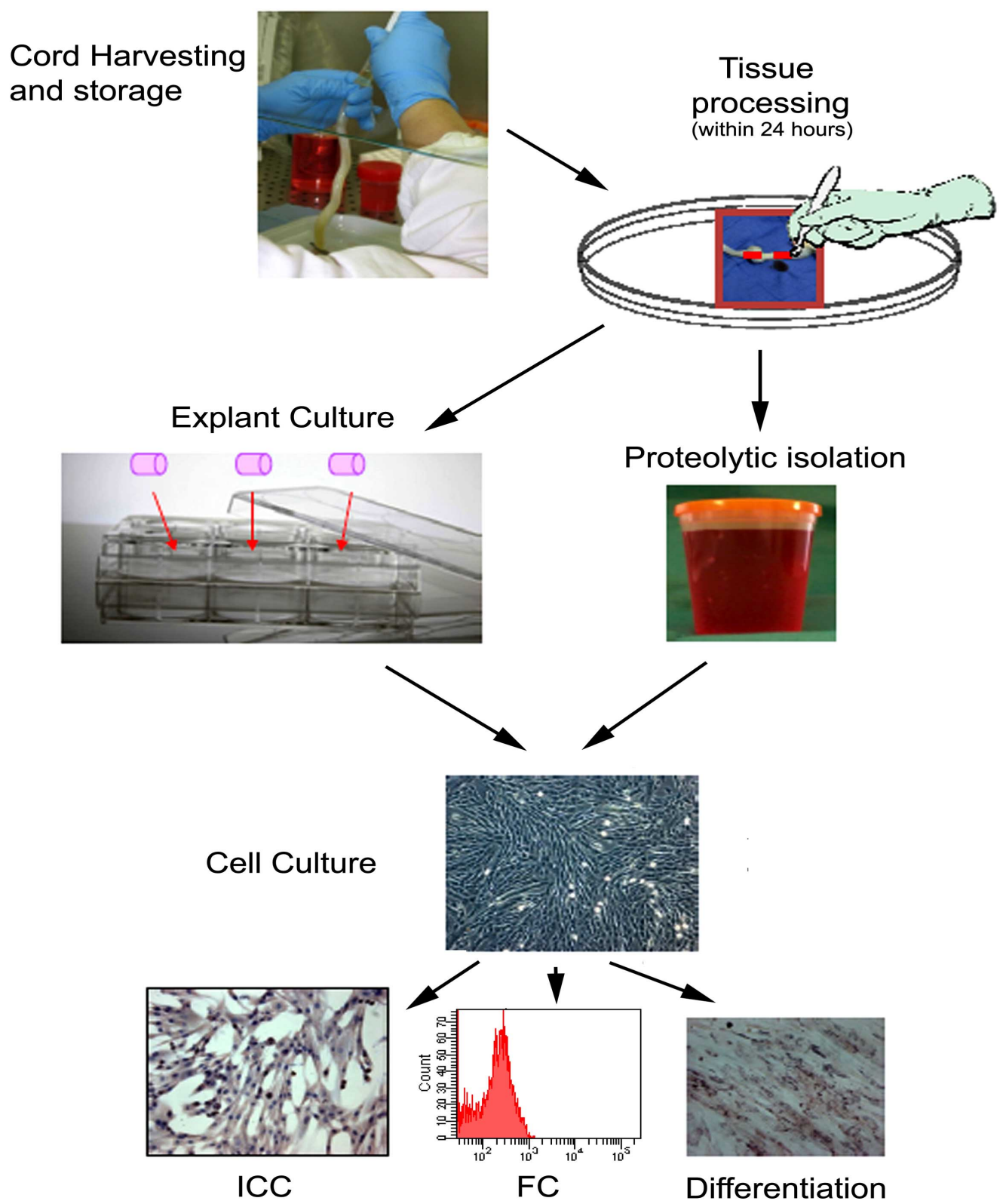

Fig. (1). Schematic representation of the steps for the isolation of MSC from Wharton's jelly. Cord harvesting and tissue processing are performed within 24 hours from delivery; then MSC may be isolated either wih explant culture, or by proteolytic digestion of whole cord fragments, with or without vessel removal. Isolated cells are easily grown on plastic, and can be further characterized for the expression of key markers (by immunocytochemistry or flow cytometry) and subjected to differentiation experiments.

The umbilical cord is delimited by a single layer of cubic epithelial cells forming the umbilical epithelium, an ectoderm derivative that continues with amniotic epithelial cells at the placental end and with the tegument epithelium of the foetus $[6,7]$. No structural borders are present between the distinct zones of UC, although it has been reported that Wharton's jelly features a relatively lower cell density than the other zones [8].

\section{WJ-MSC PHENOTYPE AND DIFFERENTIATION CAPACITY}

The presence of regions with distinctive features in the umbilical cord is reflected by the different stem cells populations which may be derived from the organ. In fact, MSC have been isolated from WJ [9], perivascular region
[10], cord blood [11], amniotic epithelium [12]. Despite their different origin, all of these cells can be reproducibly isolated, cultured and long-term stored. Moreover, there are striking phenotype similarities between these cells, since all share the core markers which allow their categorization within the growing family of MSC. To this regard, the continued research on WJ-MSC features further extended the list of expressed markers, which encompass molecules normally expressed by mature cell types derived from each of the three germ layers, as well as molecules with immunomodulatory features. WJ-MSC can be isolated from the UC matrix by means of both enzymatic digestion or enzyme-free methods (see Fig. 1). In both cases, primary populations can be expanded successfully ex vivo and further characterized and differentiated. 
Classical reports demonstrated that WJ-MSC phenotype closely resembles that of bone marrow mesenchymal stem cells (BM-MSC). WJ-MSC do express the core markers CD29, CD44, CD73, CD90, CD105, together with class Ia MHC (major histocompatibility complex) molecules (as HLA-A, -B, -C). WJ-MSC do not express hematopoietic and endothelial markers (CD34, CD45, CD31, vWF) and class II MHC (HLA-DR) as well [13-16]. In addition, WJ-MSC may express CD117 (receptor for the stem cell factor, encoded by c-Kit gene) and, differently to BM-MSC, CD68 and CD14 $[12,16,17]$.

Several mature tissue-specific markers have been also characterized in naïve WJ-MSC under standard culture conditions [18]. For example, cytoskeletal molecules of various classes such as: $\alpha$-smooth muscle actin and vimentin (mainly expressed in mesenchymal lineage cells); nestin and GFAP (glial fibrillar acidic protein) (featured by mature cells of neuroectodermal lineage); cytokeratin- $8,-18$ and -19 (expressed in endoderm-derived epithelial cells) $[16,19]$. The presence of such molecules may partly reflect the capacity of these cells to differentiate towards mature cell types derived from all three germ layers, thank to their intrinsic ability to cross germ layers boundaries: indeed, WJ-MSC are defined as multipotent stem cells since they can differentiate into at least three different cellular lineages: osteoblasts, adipocytes and chondrocytes $[19,20]$, even though their differentiative ability is largely wider [21,22].

Using specific in vitro protocols, WJ-MSC can be differentiated into glial cells and neurons [9], skeletal muscle cells [23], cardiomyocytes [24, 25], endothelial cells [26-28], hepatocytes $[29,30]$. In addition, the expression of connexin 43 [16] suggested the possibility to differentiate WJ-MSC into cardiomyocytes or other cardiac resident cell types [31] or to be directly administered to correct conduction defects and other heart diseases [32-34].

\section{RECENT DATA ON THE EXPRESSION OF RELEVANT IMMUNOMODULATORY MOLECULES IN VITRO BY MSC}

Immune modulation is viewed as a promising feature of many MSC populations, since these cells, once administered therapeutically, may be able to overcome, or at least evade, the host immune response which leads to acute or chronic rejection of the transplant.

The need of a better characterization of relevant molecules expression by MSC is further justified by the rediscovery of "old markers" (previously known to be expressed by leukocyte populations) also in perinatal MSC. We recently showed that WJ-MSC do express CD68 at both protein and mRNA level [17]. CD68 is classically known as a macrophage-specific antigen [35], even though its extramyeloid expression has been demonstrated in other cell types. [36]. In addition, recent data from Kita and coworkers suggested that cells derived from amniotic epithelium of UC do express CD14 antigen, which is known as a monocyte-specific marker $[8,12]$.

As demonstrated by an increasing number of relevant publications, a vast number of molecules with a frank immunomodulatory role are expressed by MSC, and in particular also in WJ-MSC. Literature data do exist for adult
MSC populations, as those isolated from bone marrow or adipose tissue (AT-MSC), as reported in Table 1. However, recent reports also highlighted the expression of such molecules also in many perinatal mesenchymal populations, as those derived from amniotic membrane (AM-MSC), umbilical cord lining (CL-MSC) and Wharton's jelly. Table 1 shows some of the classical and novel immunomodulatory markers which are expressed by various mesenchymal stromal cells populations.

Low level expression of class I MHC, together with lack of class II MHC and B7 co-stimulators (B7-1 or CD80 and B7-2 or CD86) highlighted a frank hypoimmunogenicity condition for MSC. Contrasting data on the expression of CD80 by MSC can further confirm MSC hypoimmunogenicity: in fact, CD80 may exert an inhibitory role on lymphocytes via CD152 (CTLA-4) binding, thus attenuating lymphocyte response [73,74]. Other authors suggested that this process may be enhanced in the absence of CD86, which binds CD28: CD86 blockade, in presence of intact CD80, results in alloantigen-specific tolerance $[75,76]$. Other members of the B7 family, with known immunomodulatory features, have been studied so far in MSC. B7$\mathrm{H} 1$ and $\mathrm{B} 7-\mathrm{H} 3$ have been demonstrated in BM-MSC and AT-MSC. We demonstrated that B7-H3 is also expressed at the protein level in human cardiac MSC [76]. In addition, we recently demonstrated that also WJ-MSC do express CD276/B7-H3 [56].

Also MHC molecules received great attention in recent years as key players of immune reactions. As depicted in Table 1, and as reported by us and others, HLA-G is expressed by WJ-MSC [16, 47] and BM-MSC [48]. HLA-G has a key role in tolerance induction of the mother's immune system towards the semi-allogeneic foetus during pregnancy; it acts together with other class Ib MHC molecules (such as HLA-E and HLA-F) and trophoblast-secreted factors as EPF (early pregnancy factor) $[77,78]$. To this regard, we recently demonstrated for the first time that WJ-MSC do express also other class Ib MHC molecules, namely HLA-E and HLA-F [45]: both are implicated in tolerogenic processes occurring at the foetomaternal interface, together with HLA-G [79-81]. Recent studies suggested additional functions for HLA-F other than antigen peptide loading [82, 83]. Both HLA-E and HLA-F share a low genetic polymorphism (i.e. very few allelic forms are known, with respect to the highly polymorphic class Ia HLA molecules) and their primary structures are highly conserved in different species, as demonstrated in primates [84]. Interestingly, other MSC populations, as cardiac-derived ones, do express both HLAE and HLA-F molecules [76]. Another recent report by Chen and co-workers confirmed our original observations about the expression of all of three class Ib HLAs by WJ-MSC [44]. HLA-E expression has been also demonstrated in CLMSC and BM-MSC, but only after challenge with TNF alpha (see Table 1) [40]. One of the suggested effects due to MSC-expressed HLA-G is the stimulation of regulatory $T$ cells (CD4+CD25+FoxP3+ Tregs). These $\mathrm{T}$ lymphocytes have been characterized as key suppressors of effector responses to alloantigens $[48,85]$. Interestingly, the action mechanisms through which HLA-G may exert this function are almost two and distinct: the membrane-bound isoform is involved in immune modulation mediated by direct 
Table 1. Comparison of Classical and Novel Immunoregulatory Molecules Expressed by Adult (BM-MSC and AT-MSC) and Perinatal (AM-MSC, CL-MSC, WJ-MSC) Stem Cells. n.a.: not Applicable

\begin{tabular}{|c|c|c|c|c|c|c|}
\hline Markers & BM-MSC & AT-MSC & AM-MSC & CL-MSC & WJ-MSC & References \\
\hline HLA-A,-B,-C & + & + & + & + & + & {$[14,16,37-42]$} \\
\hline HLA-DR & $-/+(*)$ & - & - & $-(*)$ & - & {$[14,16,39-42]$} \\
\hline HLA-E & $+(*)$ & n.a. & n.a. & $-(*)$ & + & {$[40,43-45]$} \\
\hline HLA-F & n.a. & n.a. & n.a. & n.a. & + & {$[44,45]$} \\
\hline HLA-G & + & + & + & $-(*)$ & + & {$[16,40,46-49]$} \\
\hline B7-1 CD80 & - & - & - & - & $+/-$ & {$[12,16,42,44,50,51]$} \\
\hline B7-2 CD86 & - & - & - & - & - & {$[12,16,38,42,50-52]$} \\
\hline B7-H1 (CD274) & + & n.a. & n.a. & n.a. & + & {$[53,54]$} \\
\hline B7-H3 (CD276) & + & + & n.a. & n.a. & + & {$[41,55,56]$} \\
\hline B7-H4 & + & n.a. & n.a. & n.a. & - & {$[56,57]$} \\
\hline PGE2 & + & + & + & n.a. & + & {$[58-61]$} \\
\hline LIF & + & + & + & n.a. & + & {$[62-65]$} \\
\hline $\mathrm{CD} 200$ & + & n.a. & n.a. & n.a. & + & [66-68] \\
\hline $\mathrm{CD} 271$ & + & + & + & n.a. & + & [69-72] \\
\hline
\end{tabular}

$(*)$ : The authors reported a low baseline level of expression, which was strongly upregulated after exposure to IFN- $\gamma$.

intercellular contact, while the secreted isoform (known as HLA-G5) is shedded from the cellular membrane.

The current vision of immune modulation by MSC is based on the observations linking different pathways to the suppression of lymphocyte response. Diaz-Lagares and colleagues suggested that a functional interplay between $\mathrm{NO}$ production and HLA-G expression may be effective in promoting MSC-mediated immune tolerance via HLA-G nitration [86]. Tyrosine nitration is a reaction which is accomplished through specific enzymes, and favoured by increased $\mathrm{NO}$ in the extracellular space as demonstrated in different models [26,28,87,88]. Nitration makes HLA-G sensitive to metalloproteinase (MMP)-dependent shedding. Therefore, MMP-dependent shedding of the soluble form of HLA-G may drive a paracrine mechanism of further tolerance promotion without direct cell-cell contact [86].

Other recent reports suggested that WJ-MSC do express also PGE2 (prostaglandin E2) and LIF (leukaemia inhibitory factor) $[61,65]$. Both of these molecules are able to modulate the proliferation of allogeneic lymphocytes in vitro, both in WJ-MSC and adipose tissue-derived ones.

More recently, Najar and co-workers demonstrated that both AT-MSC and WJ-MSC do express and activate the members of the CD200/CD200R pathway [68]. The CD200/CD200R axis has been reported to be important in regulating the immune responses. Engagement of CD200R by CD200 initiates an inhibitory pathway with immunosuppressive effects. The authors reported that between the tested MSC populations, WJ-MSCs did express CD200 in the greatest proportion. The concurrent expression of both molecules in $\mathrm{T}$ lymphocytes and the variations induced by inflammatory conditions on MSC expression levels, support the notion of the existence of bidirectional communications between MSC and T-lymphocytes, with potentially relevant outcomes in cellular therapy [68].

Another molecule with immunomodulatory functions is CD271. This 399 aminoacids transmembrane protein is one of the members of the TNFR (tumor necrosis factor receptor) subfamily [89]. This molecule serves as receptor for neurotrophins, such as NGF (nerve growth factor). CD271 expression was initially characterized in BM-MSC, and CD271+ cells were shown to possess immunomodulatory ability in vitro and in vivo [71]. In a very recent report, Margossian and co-workers reported the weak expression of CD271 molecule in fresh umbilical cords specimens [72].

\section{INTERACTION WITH AN INFLAMMATORY CONTEXT AND IMMUNE MODULATION IN VIVO: THE EFFECTS OF MICROENVIRONMENTAL COMPLEXITY}

A great amount of literature data strongly suggested the ability of MSC to modulate immune cells proliferation and activation in in vitro settings. These promising data were often challenged by contrasting reports regarding the generation of immune and memory responses by MSC when administered in vivo in both allogeneic and xenogeneic settings. As a general rule, literature reports of failure of MSC-mediated immune modulation may be linked either to the massive use of xenogenic models, which take in little account the relevant interspecies differences existing between immune systems, or to the use of scarcely characterized MSC populations [reviewed in 21].

In addition, recent studies may provide positive and mechanicistically-relevant data to the notion of MSCmediated immune regulation [90]. First of all, the existence of an inflammatory-primed microenvironment in a number of diseases for which cellular therapy application has been 
hypothesized, has to be taken in account. In fact, recent data showed that even though the overall expression of immunomodulatory molecules on WJ-MSC is highly similar to BM-MSC, their induction, mediated by pro-inflammatory cytokines, might differ [91]. The case of HLA-DR is exemplificative: this class II MHC may be induced in BMMSC following IFN- $\gamma$ treatment. When parallel experiments were performed using WJ-MSC, no similar upregulation was reported [40,92]. In addition, further recent data also demonstrated that WJ-MSC are able to inhibit the secretion of cytokines by peripheral blood lymphocytes, as shown for IFN- $\gamma[93]$.

Very recent data from an in vivo model of wound healing showed that WJ-MSC are able to ameliorate wound closure by the paracrine secretion of active factors, as demonstrated for TGF beta 1 and IL-10, which conversely share also potent immunomodulatory activities [94].

In another recent report, inflammation and TLR (toll-like receptor) triggering were demonstrated to have scarce effects on WJ-MSC phenotype, and differentiation ability (see below, section 5) [95].

Raicevic and co-workers, in a comparative report between MSC isolated from adipose tissue, bone marrow, and Wharton's jelly, demonstrated that the immunosuppressive potential of WJ-MSC on MLR (mixed lymphocyte reaction) was affected neither by inflammation nor by TLR triggering. This resistance was related to an overproduction of HGF (hepatocyte growth factor) by these cells [96].

$\mathrm{Ma}$ and co-workers recently reported the in vitro and in vivo data on the use of WJ-MSC in immune thrombocytopenia (ITP) patients. In vitro co-culture of $\mathrm{WJ}$ MSC with PBMCs (peripheral blood mononuclear cells) from patients did exert a suppressive action on both proliferation of autoreactive lymphocytes and destruction of autologous platelets. The authors suggested that WJ-MSC action was achieved by decreasing the co-stimulatory molecules CD80, CD40L and FasL expression. In addition, researchers demonstrated that MSC administration caused a shift in the Th1/Th2/Treg cytokines profile in ITP patients [97].

The current view on immunomodulation processes, derived from a number of recent observations, clearly shows that different biologic pathways, which are featured by MSC, contribute to the overall effect of immunomodulation. This is for example the case of MMP (matrix metalloproteinases) expression by MSC or in host tissues upon cellular therapy administration [98].

Matrix metalloproteinases constitute a broad family of matrix degrading enzymes which have been further subdivided in subfamilies based mainly on substrate specificity. These zinc-binding, calcium dependent enzymes, are typically expressed by stromal cells in mature tissues $[99,100]$, and may also be detected in body fluids in both healthy and diseased individuals [101, 102]. MMP secretion by mesenchymal cells (stromal fibroblasts) has been also linked to fibrosis amelioration in vivo [103].

Griffin et al recently showed that both upregulation of MMP activity and collagen invasion in ES (electrical stimulation)-challenged MSC could favor the process of wound healing in a mice model, with particular regard to bone fractures [104].

Recent work by Kanematsu and co-workers showed that human decidua MSC did express several enzymes of the MMP family [105].

Another recent report showed that CXCR4overexpressing MSC were able to better infiltrate infarct site in an in vivo model, and had beneficial effects on left ventricle remodeling, angiogenesis and function. The authors demonstrated that these effects were mainly due to the synthesis of MMP-9 by MSC [106].

A very recent paper by Qiu et al., elucidated the molecular mechanism at the basis of MSC migration towards inflammation sites. The authors described complement $1 \mathrm{q}$ molecule as a key chemoattractant for MSC to lesion site, and the chemoinvasion properties of MSC were due in part to the enhanced expression of MMP-2 [107].

The activity of MMP is also of key importance in differentiative processes: Studer and co-workers elucidated the roles of MMPs in hypertrophic cartilage growth, a process at the basis of bone elongation, and which may be taken in account when chondrogenic differentiation protocols are being performed using MSC [108]. It has been suggested that MMP inhibition may hamper chondrocytederived or MSC-derived matrix deposition in cartilage matrix [109]. In a very recent in vivo report, the ability of producing MMP by human MSC has been linked to the recovery of patients with osteoarthritis (OA) [110].

Yeung and colleagues investigated the mechanisms by which MSC could protect human islets from proinflammatory cytokines. Authors reported that culture of MSC with transplanted islets prevented $\beta$-cell apoptosis after cytokine treatment. Hepatocyte growth factor, MMP-2 and MMP-9 were suggested as the secreted cytoprotective factors [111].

Moreover, as reported above, another key mechanism in promoting MSC-based tolerance is the MMP-dependent shedding of the soluble form of HLA-G, driving a paracrine mechanism of long-distance tolerance promotion without direct cell-cell contact [86].

\section{IMMUNOMODULATION AND DIFFERENTIATION: CAN WE GET THEM TOGETHER FOR CELLULAR THERAPY?}

One of the bigger questions in regenerative medicine, and in general in the biology of stem cells and their progeny, is whether these cells, upon differentiation, should maintain the immunomodulatory features of the undifferentiated population.

Most reports on the hypoimmunogenicity of MSC are based on in vitro or in vivo experiments using undifferentiated cells. As discussed above, these experiments gave largely promising results. However, several issues emerged when in vivo approaches have been tried. Wharton's jelly-derived MSC constitute a population of interest for their immune features: these cells derive from a naturally immune-privileged tissue, therefore it should be also expected that stem populations could maintain a 
positional memory which may provide selective advantages to their progeny in terms of immune evasion also in an immunocompetent host. Therefore it is not surprising that, besides the above mentioned in vivo models using mainly BM-MSC, recent data on WJ-MSC further strengthened the concepts of safety and performance in the use of MSC in cell therapy. Very recently, a comparative study on the immunogenicity of human BM-MSC and UC-MSC, showed a faster rejection rate for BM-MSC. In addition, when cells were transplanted into immune deficient SCID mice, cell survival was longer for both cell populations investigated [40].

In vitro data from our group recently demonstrated that WJ-MSC do express relevant immunomodulatory molecules both in their naïve and differentiated state, as demonstrated for osteogenic, adipogenic and hepatogenic differentiation protocols [56, 57].

Another recent report by Raicevic and co-workers pointed out the potential usefulness of WJ-MSC in bone regeneration under inflammatory conditions. Even though the osteogenic differentiation ability of WJ-MSC was lower than that of BM-MSC or AT-MSC, the authors demonstrated that inflammation strongly upregulated the osteoblastdifferentiation of WJ-MSC, up to reaching the levels attained by BM-MSC. On these basis, the authors suggested that WJMSC could constitute an alternative of BM-MSC for bone regenerative applications, since WJ can provide larger amounts of MSC which may be differentiated into osteoblasts in inflammatory settings [95].

\section{CONCLUSIONS AND FUTURE PERSPECTIVES.}

WJ-MSC represent a viable alternative to BM-MSC in cellular therapy. This is due to their key properties: differentiation capacity, hypoimmunogeniciy, immunomodulatory activity, tropism for inflammatory/lesion sites. The ease of sourcing and the isolation success from nearly $100 \%$ of specimens also increase the interest towards these stem cells.

What may constitute a new and groundbreaking finding is that the usefulness of WJ-MSC may go further beyond their ability to generate mature cell types for organ repopulation following in vitro culture. In fact, these cells recently emerged as capable to stimulate in organ reparative processes by multiple mechanisms. First, WJ-MSC can secrete molecules and cytokines which can dampen local inflammatory processes. This may result in higher survival of local cells and progenitors, and may favor the self repair of tissues. In addition, secretion of matrix metalloproteinases may render these cells able to overcome fibrosis, due to the breakdown of excessive extracellular matrix deposited during the fibrotic process, and release of matrix-bound factors. In addition, MMPs may also mediate immunomodulatory processes, as shown for the shedding of HLA-G5 from the cellular membrane, thus enabling the creation of paracrine signaling cascades which can promote peripheral immune tolerance without the need of direct cellcell contact.

In addition, WJ-MSC can be banked in parallel to cord blood units. This will hopefully lead to an increase of cells available for both autologous and HLA-matched heterologous administration. Detailing the mechanicistic events which can lead to the immune privilege of WJ-MSC in vivo, with or without a parallel immune suppression, may help to define their value not only in tissue regeneration, but also in tissue repair and support of local host progenitors.

Once these key results will be achieved, it is our opinion that a new therapeutic weapon will be available to be used in the management of several diseases, with the additional advantage to be free of the ethical and safety issues which currently limit the sourcing and use of other progenitor populations.

\section{CONFLICT OF INTEREST}

Dr. La Rocca is member of the Scientific Board of Auxocell Laboratories, Inc. The funders had no role in article design, data collection, decision to publish, or preparation of the manuscript.

\section{ACKNOWLEDGEMENTS}

Authors' results referred to in this paper were in part supported by University of Palermo grants (ex 60\% 2007) to RA, FF, GLR and Istituto Euro-Mediterraneo di Scienza e Tecnologia (IEMEST) to GLR.

\section{REFERENCES}

[1] Karahuseyinoglu S, Cinar O, Kilic E, et al. Biology of stem cells in human umbilical cord stroma: in situ and in vitro surveys. Stem Cells 2007; 25: 319-31.

[2] Hoyes AD Ultrastructure of the epithelium of the human umbilical cord. J Anat 1969; 150: 149-62.

[3] McElreavey KD, Irvine AI, Ennis KT, McLean WH. Isolation, culture and characterisation of fibroblast-like cells derived from the Wharton's jelly portion of human umbilical cord. Biochem Soc Trans 1991; 19: 29S.

[4] Kobayashi K, Kubota T, Aso T. Study on myofibroblast differentiation in the stromal cells of Wharton's jelly: expression and localization of alpha-smooth muscle actin. Early Hum Dev 1998; 51: 223-33.

[5] Nanaev AK, Kohnen G, Milovanov AP, Domogatsky SP, Kaufmann P. Stromal differentiation and architecture of the human umbilical cord. Placenta 1998; 18: 53-64.

[6] Copland IB, Adamson SL, Post M, Lye SJ, Caniggia I. TGF- $\beta 3$ expression during umbilical cord development and its alteration in pre-eclampsia . Placenta 2012; 23, 311-21.

[7] Mizoguchi M, Suga Y, Sanmano B, Ikeda S, Ogawa H. Organotypic culture and surface plantation using umbilical cord epithelial cells: morphogenesis and expression of differentiation markers mimicking cutaneous epidermis. J Dermatol Sci 2004; 35 : 199-206.

[8] Jeschke MG, Gauglitz GG, Phan TT, Herndon DN, Kita K. Umbilical Cord Lining Membrane and Wharton's Jelly-Derived Mesenchymal Stem Cells: the Similarities and Differences. Open Tissue Eng Regen Med J 2011; 4: 21-7.

[9] Mitchell KE, Weiss ML, Mitchell BM, et al. Matrix cells from Wharton's jelly form neurons and glia. Stem Cells 2003; 21: 50-60.

[10] Sarugaser R, Lickorish D, Baksh D, Hosseini MM, Davies JE. Human umbilical cord perivascular (HUCPV) cells: a source of mesenchymal progenitors. Stem Cells 2005; 23: 220-9.

[11] Campagnoli C, Roberts IA, Kumar S, Bennett PR, Bellantuono I, Fisk NM. Identification of mesenchymal stem/progenitor cells in human first-trimester fetal blood, liver, and bone marrow. Blood 2001; 98: 2396-402.

[12] Kita K, Gauglitz GG, Phan TT, Herndon DN, Jeschke MG. Isolation and characterization of mesenchymal stem cells from the sub-amniotic human umbilical cord lining membrane. Stem Cells Dev 2010; 19: 491-502.

[13] Wang H-S, Hung S-C, Peng S-T, et al. Mesenchymal stem cells in the Wharton's jelly of the human umbilical cord. Stem Cells 2004; 22: $1330-7$. 
[14] Weiss ML, Medicetty S, Bledsoe AR, et al. Human umbilical cord matrix stem cells: Preliminary characterization and effect of transplantation in a rodent model of Parkinson's disease. Stem Cells 2006; 24: 781-92.

[15] Lu LL, Liu Yj, Yang SG, et al. Isolation and characterization of human umbilical cord mesenchymal stem cells with hematopoietic supportive function and other potentials. Haematologica 2006; 91: 1017-26.

[16] La Rocca G, Anzalone R, Corrao S, et al. Isolation and characterization of Oct-4+/HLA-G+ mesenchymal stem cells from human umbilical cord matrix: differentiation potential and detection of new markers. Histochem Cell Biol 2009; 131: 267-82.

[17] La Rocca G, Anzalone R, Farina F. The expression of CD68 in human umbilical cord mesenchymal stem cells: New evidences of presence in non-myeloid cell types. Scand J Immunol 2009; 70: 161-2.

[18] Huang Y, Parolini O, La Rocca G, Deng L. Umbilical cord versus bone marrow-derived mesenchymal stromal cells. Stem Cells Dev 2012; 21(5): 2900-3.

[19] Lo Iacono M, Anzalone R, Corrao S, et al. Perinatal and Wharton's Jelly-Derived Mesenchymal Stem Cells in Cartilage Regenerative Medicine and Tissue Engineering Strategies. Open Tissue Eng Regen Med J 2011; 4: 72-81.

[20] Dominici M, Le Blanc K, Mueller I et al. E. Minimal criteria for defining multipotent mesenchymal stromal cells. The international society for cellular therapy position statement. Cytotherapy 2006; 8: 315-7.

[21] Anzalone R, Lo Iacono M, Loria $\mathrm{T}$, et al. Wharton's jelly mesenchymal stem cells as candidates for beta cells regeneration: Extending the differentiative and immunomodulatory benefits of adult mesenchymal stem cells for the treatment of type 1 diabetes. Stem Cell Rev Rep 2011; 7: 342-63.

[22] Anzalone R, Farina F, Zummo G, La Rocca G. Recent patents and advances on isolation and cellular therapy applications of mesenchymal stem cells from human umbilical cord Wharton's jelly. Rec Pat Regen Med 2011; 1: 216-27.

[23] Conconi MT, Burra P, Di Liddo R, et al. CD105(+) cells from Wharton's jelly show in vitro and in vivo myogenic differentiative potential. Int J Mol Med 2006; 18: 1089-96.

[24] Pereira WC, Khushnooma I, Madkaikar M, Ghosh K. Reproducible methodology for the isolation of mesenchymal stem cells from human umbilical cord and its potential for cardiomyocyte generation. J Tissue Eng Regen Med 2008; 2: 394-9.

[25] Hollweck T, Hartmann I, Eblenkamp $\mathrm{M}$, et al. Cardiac differentiation of human wharton`s jelly stem cells - experimental comparison of protocols. Open Tissue Eng Regen Med J 2011; 4: 95-102.

[26] Anzalone R, La Rocca G, Di Stefano A, et al. Role of endothelial cell stress in the pathogenesis of chronic heart failure. Front Biosci 2009; 14: 2238-47.

[27] Alaminos M, Pérez-Köhler B, Garzón I, et al. Transdifferentiation potentiality of human Wharton's jelly stem cells towards vascular endothelial cells. J Cell Physiol 2010; 223: 640-7.

[28] La Rocca G, Di Stefano A, Eleuteri E, et al. Oxidative stress induces myeloperoxidase expression in endocardial endothelial cells from patients with chronic heart failure. Basic Res Cardiol 2009; 104: 307-20.

[29] Campard D, Lysy PA, Najimi M, Sokal EM. Native umbilical cord matrix stem cells express hepatic markers and differentiate into hepatocyte-like cells. Gastroenterology 2008; 134: 833-48.

[30] Anzalone R, Lo Iacono M, Corrao S, et al. New emerging potentials for human Wharton's jelly mesenchymal stem cells: immunological features and hepatocyte-like differentiative capacity. Stem Cells Dev 2010; 19: 423-38.

[31] Semenov OV, Breymann C. Mesenchymal stem cells derived from wharton's jelly and their potential for cardio-vascular tissue engineering. Open Tissue Eng Regen Med J 2011; 4: 64-71.

[32] Yokokawa M, Ohnishi S, Ishibashi-Ueda H, et al. Transplantation of mesenchymal stem cells improves atrioventricular conduction in a rat model of complete atrioventricular block. Cell Transplant 2008; 17: 1145-55.

[33] Turillazzi E, La Rocca G, Anzalone R, et al. Heterozygous nonsense SCN5A mutation W822X explains a simultaneous sudden infant death syndrome. Virchows Arch 2008; 453: 209-16.

[34] Turillazzi E, Pomara C, La Rocca G, et al. Immunohistochemical marker for $\mathrm{Na}+\mathrm{CP}$ type Valpha (C-20) and heterozygous nonsense
SCN5A mutation W822X in a sudden cardiac death induced by mild anaphylactic reaction. Appl Immunohistochem Mol Morphol 2009; 17: 357-62.

[35] Micklem K, Rigney E, Cordell J, et al. A human macrophageassociated antigen (CD68) detected by six different monoclonal antibodies. Br J Haematol 1989; 73: 6-11.

[36] Gottfried E, Kunz-Schughart LA, Weber A, et al. Expression of CD68 in non-myeloid cell types. Scand J Immunol 2008; 67: 45363.

[37] Turnovcova K, Ruzickova K, Vanecek V, Sykova E, Jendelova P. Properties and growth of human bone marrow mesenchymal stromal cells cultivated in different media. Cytotherapy 2009; 11: 874-85.

[38] Troyer DL, Weiss ML. Wharton's jelly-derived cells are a primitive stromal cell population. Stem Cells 2008; 26: 591-9.

[39] Wang HS, Hung SC, Peng ST, et al. Mesenchymal stem cells in the Wharton's jelly of the human umbilical cord. Stem Cells 2004; 22: 1330-7.

[40] Deuse T, Stubbendorff M, Tang-Quan K, et al. Immunogenicity and immunomodulatory properties of umbilical cord lining mesenchymal stem cells. Cell Transplant 2011; 20: 655-67.

[41] Al-Nbaheen M, Vishnubalaji R, Ali D, et al. Human stromal (mesenchymal) stem cells from bone marrow, adipose tissue and skin exhibit differences in molecular phenotype and differentiation potential. Stem Cell Rev Rep 2012; doi:10.1007/s12015-012-93658

[42] Magatti M, De Munari S, Vertua E, Gibelli L, Wengler GS, Parolini O. Human amnion mesenchyme harbors cells with allogeneic T-cell suppression and stimulation capabilities. Stem Cells 2008; 26:182-92.

[43] Götherström C, West A, Liden J, Uzunel M, Lahesmaa R, Le Blanc $\mathrm{K}$. Difference in gene expression between human fetal liver and adult bone marrow mesenchymal stem cells. Haematologica 2005; 90:1017-26.

[44] Chen H, Zhang N, Li T, et al. Human umbilical cord Wharton's jelly stem cells: immune property genes assay and effect of transplantation on the immune cells of heart failure patients. Cell Immunol 2012; 276: 83-90.

[45] Anzalone R, Lo Iacono M, Corrao S, et al. Human Wharton's jellyderived mesenchymal stem cells express several immunomodulatory molecules both in their naïve state and hepatocyte-like differentiated progeny: prospects for their use in liver diseases. Placenta 2011;32(Supplement 4): S335.

[46] Weiss ML, Anderson C, Medicetty S, et al. Immune properties of human umbilical cord Wharton's jelly-derived cells. Stem Cells 2008; 26: 2865-74

[47] Selmani Z, Naji A, Zidi I, et al. Human leukocyte antigen-G5 secretion by human mesenchymal stem cells is required to suppress $\mathrm{T}$ lymphocyte and natural killer function and to induce CD4+CD25highFOXP3+ regulatory T cells. Stem Cells 2008; 26: 212-22.

[48] Lee JM, Jung J, Lee HJ, et al. Comparison of immunomodulatory effects of placenta mesenchymal stem cells with bone marrow and adipose mesenchymal stem cells. Int Immunopharmacol 2012; 13 : 219-24.

[49] Banas RA, Trumpower C, Bentlejewski C, Marshall V, Sing G, Zeevi A. Immunogenicity and immunomodulatory effects of amnion-derived multipotent progenitor cells. Hum Immunol 2008; 69: 321-8.

[50] Deans RJ, Moseley AB. Mesenchymal stem cells: biology and potential clinical uses. Exp Hematol 2000; 28: 875-84.

[51] Hoogduijn MJ, Crop MJ, Peeters AM, et al. Human heart, spleen, and perirenal fat-derived mesenchymal stem cells have immunomodulatory capacities. Stem Cells Dev 2007; 16: 597-604.

[52] Xu W, Zhang X, Qian H, et al. Mesenchymal stem cells from adult human bone marrow differentiate into a cardiomyocyte phenotype in vitro. Exp Biol Med 2004; 229: 623-31.

[53] Sheng H, Wang Y, Jin Y, et al. A critical role of IFNgamma in priming MSC-mediated suppression of $\mathrm{T}$ cell proliferation through up-regulation of B7-H1. Cell Res 2008; 18: 846-57.

[54] Tipnis S, Viswanathan C, Majumdar AS. Immunosuppressive properties of human umbilical cord-derived mesenchymal stem cells: role of B7-H1 and IDO. Immunol Cell Biol 2010; 88: 795806. 
[55] Niehage C, Steenblock C, Pursche T, Bornhäuser M, Corbeil D, Hoflack B. The cell surface proteome of human mesenchymal stromal cells. PLoS One 2011; 6: e20399.

[56] Lo Iacono M, Anzalone R, Corrao S, Zummo G, Farina F, La Rocca G. Non-classical type I HLAs and B7 costimulators revisited: analysis of expression and immunomodulatory role in undifferentiated and differentiated MSC isolated from human umbilical cord Wharton's jelly. Histol Histopathol 2011; 26(Supplement 1): 313.

[57] Xue Q, Luan XY, Gu YZ, et al. The negative co-signaling molecule b7-h4 is expressed by human bone marrow-derived mesenchymal stem cells and mediates its T-cell modulatory activity. Stem Cells Dev 2010; 19: 27-38.

[58] Németh K, Leelahavanichkul A, Yuen PS, et al. Bone marrow stromal cells attenuate sepsis via prostaglandin E(2)-dependent reprogramming of host macrophages to increase their interleukin10 production. Nat Med 2009; 15: 42-9.

[59] Yañez R, Oviedo A, Aldea M, Bueren JA, Lamana ML. Prostaglandin E2 plays a key role in the immunosuppressive properties of adipose and bone marrow tissue-derived mesenchymal stromal cells. Exp Cell Res 2010; 316: 3109-23.

[60] Kang JW, Koo HC, Hwang SY, et al. Immunomodulatory effects of human amniotic membrane-derived mesenchymal stem cells. J Vet Sci 2012; 13: 23-31.

[61] Najar M, Raicevic G, Boufker HI, et al. Mesenchymal stromal cells use PGE2 to modulate activation and proliferation of lymphocyte subsets: Combined comparison of adipose tissue, Wharton's Jelly and bone marrow sources. Cell Immunol 2010; 264: 171-9.

[62] Liu T, Guo L, Liu Z, Cheng W. Human amniotic epithelial cells maintain mouse spermatogonial stem cells in an undifferentiated state due to high leukemia inhibitor factor (LIF) expression. in Vitro Cell Dev Biol Anim 2011; 47: 318-26.

[63] Mathieu ME, Saucourt C, Mournetas V, et al. LIF-dependent signaling: new pieces in the Lego. Stem Cell Rev Rep 2012; 8: 115.

[64] Potdar PD, D'Souza SB. Ascorbic acid induces in vitro proliferation of human subcutaneous adipose tissue derived mesenchymal stem cells with upregulation of embryonic stem cell pluripotency markers Oct4 and SOX 2. Hum Cell 2010; 23: 152-5.

[65] Najar M, Raicevic G, Boufker HI, et al. Adipose-tissue-derived and Wharton's jelly-derived mesenchymal stromal cells suppress lymphocyte responses by secreting leukemia inhibitory factor. Tissue Eng Part A 2010; 16: 3537-46.

[66] Pietilä M, Lehtonen S, Tuovinen E, et al. CD200 positive human mesenchymal stem cells suppress tnf-alpha secretion from cd200 receptor positive macrophage-like cells. PLoS One 2012; 7: e31671.

[67] Delorme B, Ringe J, Gallay N, et al. Specific plasma membrane protein phenotype of culture-amplified and native human bone marrow mesenchymal stem cells. Blood 2008; 111: 2631-5.

[68] Najar M, Raicevic G, Jebbawi F, et al. Characterization and functionality of the CD200-CD200R system during mesenchymal stromal cell interactions with T-lymphocytes. Immunol Lett 2012; 146: 50-6.

[69] Soncini M, Vertua E, Gibelli L, et al. Isolation and characterization of mesenchymal cells from human fetal membranes. J Tissue Eng Regen Med 2007; 1: 296-305.

[70] Quirici N, Scavullo C, de Girolamo L, Lopa S, Arrigoni E, Deliliers GL, Brini AT. Anti-L-NGFR and -CD34 monoclonal antibodies identify multipotent mesenchymal stem cells in human adipose tissue. Stem Cells Dev 2010; 19: 915-25.

[71] Kuçi S, Kuçi Z, Kreyenberg H, et al. CD271 antigen defines a subset of multipotent stromal cells with immunosuppressive and lymphohematopoietic engraftment-promoting properties. Haematologica 2010; 95: 651-9.

[72] Margossian T, Reppel L, Makdissy N, Stoltz JF, Bensoussan D, Huselstein C. Mesenchymal stem cells derived from Wharton's jelly: Comparative phenotype analysis between tissue and in vitro expansion. Biomed Mater Eng 2012; 22: 243-54.

[73] Smith M, Bittner JG 4th, White S, Smith D, Horuzsko A. HLA-Gtreated tolerogenic dendritic cells induce tolerogenic potential by increasing expression of B7-1 (CD80) molecules. Transplant Proc 2008; 40: 1598-603.

[74] Kurtz J, Raval F, Vallot C, Der J, Sykes M. CTLA-4 on alloreactive $\mathrm{CD} 4 \mathrm{~T}$ cells interacts with recipient $\mathrm{CD} 80 / 86$ to promote tolerance. Blood 2009; 113: 3475-84.
[75] Zhu X-Y, Zhou Y-H, Wang M-Y, Jin L-P, Yuan M-M, Li D-J. Blockade of CD86 signaling facilitates a Th2 bias at the maternalfetal interface and expands peripheral $\mathrm{CD} 4+\mathrm{CD} 25+$ regulatory $\mathrm{T}$ cells to rescue abortion-prone fetuses. Biol Reprod 2005; 72: 33845.

[76] Anzalone R, Corrao S, Lo Iacono $\mathrm{M}$, et al. Isolation and characterization of CD276+/HLA-E + human sub-endocardial mesenchymal stem cells from chronic heart failure patients: analysis of differentiative potential and immunomodulatory markers expression. Stem Cells Dev 2012; doi:10.1089/scd.2012.0402.

[77] Cappello F, Czarnecka AM, La Rocca G, Di Stefano A, Zummo G, Macario AJ. Hsp60 and Hspl0 as antitumor molecular agents. Cancer Biol Ther 2007; 6: 487-9.

[78] Corrao S, Campanella C, Anzalone R, et al. Human Hsp10 and Early Pregnancy Factor (EPF) and their relationship and involvement in cancer and immunity: current knowledge and perspectives. Life Sci 2010; 86: 145-52.

[79] Lee N, Llano M, Carretero M, et al. HLA-E is a major ligand for the natural killer inhibitory receptor CD94/NKG2A. Proc Natl Acad Sci USA 1998; 95: 5199-204.

[80] Ishitani A, Sageshima N, Lee N, et al. Protein expression and peptide binding suggest unique and interacting functional roles for HLA-E, F, and $\mathrm{G}$ in maternal-placental immune recognition. $\mathrm{J}$ Immunol 2003; 171: 1376-84

[81] Shobu T, Sageshima N, Tokui H, et al. The surface expression of HLA-F on decidual trophoblasts increases from mid to term gestation. J Reprod Immunol 2006; 72: 18-32.

[82] Boyle LH, Gillingham AK, Munro S, Trowsdale J. Selective export of HLA-F by its cytoplasmic tail. J Immunol 2006; 176: 6464-72.

[83] Goodridge JP, Burian A, Lee N, Geraghty DE. HLA-F complex without peptide binds to MHC class I protein in the open conformer form. J Immunol 2010; 184: 6199-208.

[84] Parham P, Norman PJ, Abi-Rached L, Guethlein LA. Humanspecific evolution of killer cell immunoglobulin-like receptor recognition of major histocompatibility complex class I molecule. Philos Trans R Soc B 2012; 367: 800-11.

[85] Griffin MD, Ritter T, Mahon BP. Immunological aspects of allogeneic mesenchymal stem cell therapies. Human Gene Ther 2010; 21: 1641-55.

[86] Díaz-Lagares A, Alegre E, LeMaoult J, Carosella ED, González A. Nitric oxide produces HLA-G nitration and induces metalloprotease-dependent shedding creating a tolerogenic milieu. Immunology 2009; 126: 436-45.

[87] Eleuteri E, Magno F, Gnemmi I, et al. Role of oxidative and nitrosative stress biomarkers in chronic heart failure. Front Biosci 2009; 14: 2230-7.

[88] Eleuteri E, Di Stefano A, Ricciardolo FL, et al. Increased nitrotyrosine plasma levels in relation to systemic markers of inflammation and myeloperoxidase in chronic heart failure. Int $\mathbf{J}$ Cardiol 2009; 135: 386-90.

[89] Rogers ML, Beare A, Zola H, Rush RA. Cd271 (P75 neurotrophin receptor). J Biol Regul Homeost Agents 2008; 22: 1-6.

[90] La Rocca G. Connecting the dots: the promises of Wharton's jelly mesenchymal stem cells for tissue repair and regeneration. Open Tissue Eng Regen Med J 2011; 4: 3-5.

[91] Prasanna SJ, Jahnavi VS. Wharton's Jelly Mesenchymal Stem Cells as Off-The-Shelf Cellular Therapeutics: A Closer Look into their Regenerative and Immunomodulatory Properties. Open Tissue Eng Regen Med J 2011; 4: 28-38

[92] Prasanna SJ, Gopalakrishnan D, Shankar SR, Vasandan AB. Proinflammatory cytokines, IFNgamma and TNFalpha, influence immune properties of human bone marrow and Wharton jelly mesenchymal stem cells differentially. PLoS One 2010; 5: e9016.

[93] Zhou C, Yang B, Tian Y, et al. Immunomodulatory effect of human umbilical cord Wharton's jelly-derived mesenchymal stem cells on lymphocytes. Cell Immunol 2011; 272: 33-8.

[94] Shohara R, Yamamoto A, Takikawa S, Iwase A, Hibi H, Kikkawa F, Ueda M. Mesenchymal stromal cells of human umbilical cord Wharton's jelly accelerate wound healing by paracrine mechanisms. Cytotherapy 2012; 14(10): 1171-81.

[95] Raicevic G, Najar M, Pieters K, et al. Inflammation and toll-like receptor ligation differentially affect the osteogenic potential of human mesenchymal stromal cells depending on their tissue origin. Tissue Eng Part A 2012; 18: 1410-8. 
[96] Raicevic G, Najar M, Stamatopoulos B, et al. The source of human mesenchymal stromal cells influences their TLR profile as well as their functional properties. Cell Immunol 2011; 270: 207-16.

[97] Ma L, Zhou Z, Zhang D, et al. Immunosuppressive function of mesenchymal stem cells from human umbilical cord matrix in immune thrombocytopenia patients. Thromb Haemost 2012; 107: 937-50.

[98] De Miguel MP, Fuentes-Julián S, Blázquez-Martínez A, et al. Immunosuppressive properties of mesenchymal stem cells: advances and applications. Curr Mol Med 2012; 12: 574-91.

[99] Turner NA, Porter KE. Regulation of myocardial matrix metalloproteinase expression and activity by cardiac fibroblasts. IUBMB Life 2012; 64: 143-50.

[100] La Rocca G, Anzalone R, Magno F, Farina F, Cappello F, Zummo G. Cigarette smoke exposure inhibits extracellular MMP-2 (gelatinase A) activity in human lung fibroblasts. Respir Res 2007; 8: 23.

[101] La Rocca G, Pucci-Minafra I, Marrazzo A, Taormina P, Minafra S. Zymographic detection and clinical correlations of MMP-2 and MMP-9 in breast cancer sera. Br J Cancer 2004; 90: 1414-21.

[102] Pucci-Minafra I, Minafra S, La Rocca G, et al. Zymographic analysis of circulating and tissue forms of colon carcinoma gelatinase A (MMP-2) and B (MMP-9) separated by mono- and two-dimensional electrophoresis. Matrix Biol 2001; 20: 419-27.

[103] Pitiyage GN, Slijepcevic P, Gabrani A, et al. Senescent mesenchymal cells accumulate in human fibrosis by a telomereindependent mechanism and ameliorate fibrosis through matrix metalloproteinases. J Pathol 2011; 223: 604-17.
[104] Griffin M, Iqbal SA, Sebastian A, Colthurst J, Bayat A. Degenerate wave and capacitive coupling increase human MSC invasion and proliferation while reducing cytotoxicity in an in vitro wound healing model. PLoS One 2011; 6: e23404.

[105] Kanematsu D, Shofuda T, Yamamoto A, et al. Isolation and cellular properties of mesenchymal cells derived from the decidua of human term placenta. Differentiation 2011; 82: 77-88.

[106] Huang W, Wang T, Zhang D, et al. Mesenchymal stem cells overexpressing CXCR4 attenuate remodeling of postmyocardial infarction by releasing matrix metalloproteinase-9. Stem Cells Dev 2012; 21: 778-89.

[107] Qiu Y, Marquez-Curtis LA, Janowska-Wieczorek A. Mesenchymal stromal cells derived from umbilical cord blood migrate in response to complement C1q. Cytotherapy 2012; 14: 285-95.

[108] Studer D, Millan C, Oztürk E, Maniura-Weber K, Zenobi-Wong M. Molecular and biophysical mechanisms regulating hypertrophic differentiation in chondrocytes and mesenchymal stem cells. Eur Cell Mater 2012; 24: 118-35.

[109] Li H, Feng F, Bingham CO 3rd, Elisseeff JH. Matrix metalloproteinases and inhibitors in cartilage tissue engineering. J Tissue Eng Regen Med 2012; 6: 144-54.

[110] Davatchi F, Abdollahi BS, Mohyeddin M, Shahram F, Nikbin B. Mesenchymal stem cell therapy for knee osteoarthritis. Preliminary report of four patients. Int J Rheum Dis 2011; 14: 211-5.

[111] Yeung TY, Seeberger KL, Kin T, et al. Human mesenchymal stem cells protect human islets from pro-inflammatory cytokines. PLoS One 2012; 7: e38189.

(C) La Rocca et al.; Licensee Bentham Open.

This is an open access article licensed under the terms of the Creative Commons Attribution Non-Commercial License (http: //creativecommons.org/licenses/by$\mathrm{nc} / 3.0 /$ ), which permits unrestricted, non-commercial use, distribution and reproduction in any medium, provided the work is properly cited. 